\title{
Keratinocyte growth factor induces vascular endothelial growth factor-A expression in colorectal cancer cells
}

\author{
KOSUKE NARITA ${ }^{1}$, TAKENORI FUJII ${ }^{2}$, TOSHIYUKI ISHIWATA ${ }^{2}$, TETSUSHI YAMAMOTO ${ }^{2}$, \\ YOKO KAWAMOTO $^{2}$, KIYOKO KAWAHARA ${ }^{2}$, NANDO NAKAZAWA ${ }^{2}$ and ZENYA NAITO $^{2}$ \\ ${ }^{1}$ School of Medicine, ${ }^{2}$ Department of Pathology, Integrative Oncological \\ Pathology, Nippon Medical School, Tokyo 113-8602, Japan
}

Received August 11, 2008; Accepted October 17, 2008

DOI: 10.3892/ijo_00000158

\begin{abstract}
Keratinocyte growth factor (KGF), which is also called fibroblast growth factor (FGF)-7, belongs to the FGF family. KGF is not commonly produced by human cancer cells, but the KGF receptor (KGFR) is expressed in most cancer cells and particularly highly expressed in well-differentiated types of cancer. Recently, it has been reported that vascular endothelial growth factor (VEGF)-A expression is induced by $\mathrm{KGF}$ in pancreatic cancer cells. VEGF-A is produced by some cancer cells and plays important roles in the angiogenesis and metastasis of cancer cells including those in the colorectum. In this study, we examined whether recombinant human KGF (rhKGF) induces major angiogenic growth factors including VEGF-A, FGF-2 and hepatocyte growth factor (HGF) in human colorectal cancer cells (HCT-15), which express a high level of KGFR, but a low or negligible level of KGF. rhKGF significantly increased the VEGF-A expression level in a serum-free medium of HCT-15 cells, but FGF-2 and HGF expression levels were too low to detect. Furthermore, the expression levels of the angiogenic growth factors were evaluated in KGF-transfected HCT-15 cells, which were induced to stably overexpress KGF by KGF gene transfection and mock-transfected cells (Mock). KGF and VEGF-A expression levels in the cells and the protein concentrations in serum-free medium were significantly higher in KGF-transfected HCT-15 cells than in Mock cells. In contrast, the FGF-2 and HGF mRNA expression levels were not significantly different between KGF-transfected HCT-15 cells and Mock cells and the protein concentrations in serum-free medium of the cells were below the detection level. These findings suggest that administration of rhKGF and over-expression of endogenous KGF genes in colorectal
\end{abstract}

Correspondence to: Dr Toshiyuki Ishiwata, Department of Pathology, Integrative Oncological Pathology, Nippon Medical School, Tokyo 113-8602, Japan

E-mail: ishiwata@nms.ac.jp

Key words: keratinocyte growth factor, tumor angiogenesis, vascular endothelial growth factor-A, fibroblast growth factor-2, hepatocyte growth factor, colorectal cancer cancer cells increase VEGF-A production and may relate to angiogenesis in cancer.

\section{Introduction}

Keratinocyte growth factor (KGF), which is also known as fibroblast growth factor (FGF)-7, has been identified in a human embryonic lung fibroblast cell line $(1,2)$. KGF is mainly produced by mesenchymal cells and affects epithelial cells that specifically express the KGF receptor (KGFR) (3). KGFR is tyrosine kinase FGF receptor-2 (FGFR-2) IIIb, which is a spliced variant of FGFR-2 (4). KGF was previously reported to modulate proliferation, differentiation, migration of cells and cell adhesion to extracellular matrices $(5,6)$. KGF plays important roles in the wound healing of skin, proliferation of gut epithelial cells and angiogenesis in the rat cornea (7).

There are a few studies on human cancer cells producing KGF (8-11). In contrast, the expression of KGFR has been reported in various cancer cells (12). KGFR expression in cancer cells correlated to a well-differentiated histological type of esophageal cancer and early-type macroscopic findings, shallow wall invasion and expansive growth type of gastric cancer $(8,13)$. Similarly, KGFR expression was associated with a well-differentiated histological type and shallow wall invasion in colorectal cancer (14). These findings suggest that KGFR expression in cancer cells does not directly correlate to the aggressiveness of cell growth. On the other hand, the coexpression of KGF and KGFR in endometrial, pancreatic, esophageal and colorectal cancer cells was reported (8-11). Recently, our group has found that the coexpression of KGF and KGFR in cancer cells is significantly associated with VEGF-A expression and venous invasion of pancreatic cancer cells (10). Moreover, exogenous KGF enhances vascular endothelial growth factor (VEGF)-A expression and release in pancreatic cancer cell lines. These lines of evidence suggest that KGF is closely related to the expression of angiogenic growth factor and indirectly contributes to tumor growth.

Several types of growth factors contribute to tumor angiogenesis and VEGF-A, FGF-2/basic FGF and hepatocyte growth factor (HGF) are considered to be important angiogenic growth factors for the formation of microvessels adjacent to cancer cells (15). VEGF-A stimulates vascular endothelial cells, but not epithelial or stromal cells (16). In addition to vascular endothelial cells, FGF-2 stimulates the growth of 
stromal fibroblasts and HGF stimulates the growth of epithelial cells (17-19). These growth factors are often expressed by tumor cells and they modulate the components and functions of the extracellular matrices close to cancer cells (20). These microvessels are considered to supply oxygen and nutrition to cancer cells and contribute to tumor growth $(21,22)$. Furthermore, the microvessels are reported as one of the main pathways for distant metastases of cancer cells (23).

In this study, we examined whether KGF induces the expression of major angiogenic growth factors in colorectal cancer cells. We now report that KGF induces VEGF-A expression but does not affect FGF-2 and HGF expression in colorectal cancer cells.

\section{Materials and methods}

Materials. The following were purchased: an RNeasy mini kit from Qiagen GmbH (Hilden, Germany), a Transcriptor firststrand cDNA synthesis kit, LightCycler FastStart DNA Master SYBR-Green I and FuGENE 6 transfection reagent from Roche Diagnostics GmbH (Mannheim, Germany); Human VEGF, HGF, KGF/FGF-7 and FGF basic Quantikine colorimetric sandwich enzyme-linked immunosorbent assay (ELISA) kits, recombinant human KGF (rhKGF) and goat polyclonal anti-FGF-7 antibodies from R\&D Systems Inc. (Westerville, OH, USA); rabbit polyclonal anti-VEGF-A antibodies (A-20) from Santa Cruz Biotech. (Santa Cruz, CA, USA); Texas Red-conjugated anti-rabbit IgG from Molecular Probes (Eugene, OR, USA); Texas Red-conjugated streptavidine and Vectashield mounting medium containing 4', 6diamidino-2-phenylindole dihydrochloride (DAPI) from Vector Laboratories, Inc. (Burlingame, CA, USA); pIRES2EGFP from BD Bioscience Clontech (Palo Alto, CA, USA). All other chemicals and reagents were purchased from Sigma Chemical Corp. (St. Louis, MO, USA).

Colorectal cancer cell line. The human colorectal cancer cell line HCT-15 was obtained from the Institute of Development, Aging and Cancer, Tohoku University (Sendai, Japan). The cells were cultured in RPMI-1640 medium supplemented with $10 \%$ heat-inactivated fetal bovine serum (FBS), $100 \mathrm{U} / \mathrm{ml}$ penicillin and $100 \mu \mathrm{g} / \mathrm{ml}$ streptomycin at $37^{\circ} \mathrm{C}$ under a humidified $5 \% \mathrm{CO}_{2}$ atmosphere. The colorectal cancer cells expressed a high level of KGFR and a very low or a negligible level of KGF (24).

Effect of recombinant human KGF on angiogenic growth factor expression. Wild-type HCT-15 cells ( $1 \times 10^{5} /$ well), which were plated in six-well plates, were grown in $2 \mathrm{ml}$ of RPMI1640 medium with $10 \%$ FBS for $24 \mathrm{~h}$ and then cultured in serum-free medium for $48 \mathrm{~h}$. The cells were subsequently cultured in serum-free RPMI-1640 medium with or without $10 \mathrm{ng} / \mathrm{ml}$ recombinant human KGF (rhKGF) for $48 \mathrm{~h}$. Angiogenic growth factors including VEGF-A, FGF-2 and HGF proteins in the culture supernatant were examined using a sandwich ELISA kit, in accordance with the protocol of the manufacturer.

KGF gene transfection. KGF-transfected HCT-15 cells, which were induced to stably overexpress KGF by KGF gene transfection, were prepared as previously reported (24). Briefly, the full-length sequence of human KGF cDNA was obtained by the reverse transcription-polymerase chain reaction (RT-PCR) method. The KGF cDNA was cloned into an expression vector, pIRES2-EGFP and the integrity of the insert was confirmed by dideoxy-terminator sequencing. The pIRES2-KGF-EGFP recombinant plasmid was transfected into HCT-15 cells and the cells were selected using $200 \mu \mathrm{g} / \mathrm{ml}$ G418. The HCT-15 cells that had been transfected with the vector alone were designated as Mock cells. Individual resistant colonies were isolated using a cloning ring.

Quantitative real-time PCR (Q-PCR) analysis. KGFtransfected HCT-15 cells and Mock cells (1x105/well) plated in six-well plates were grown in $2 \mathrm{ml}$ of RPMI-1640 medium with $10 \%$ FBS for $24 \mathrm{~h}$ and then cultured in serum-free medium for $48 \mathrm{~h}$. Total RNA was extracted from the cancer cells using an RNeasy mini kit. cDNA was synthesized using a Transcriptor first-strand cDNA synthesis kit following the manufacturer's protocol. Quantitative real-time PCR (Q-PCR) analysis was performed using a LightCycler-FastStart DNA Master SYBR-Green I system. The real-time PCR primers used for KGF corresponded to nts 765-784 (5'-TTG-TGGCAA-TCA-AAG-GGG-TG-3') and nts 905-927 (5'-CCTCCG-TTG-TGT-GTC-CAT-TTA-GC-3') of human KGF cDNA (163 bp, NM_002009). The PCR primers used for VEGF-A corresponded to nts 1126-1148 (5'-GAG-GAGGGC-AGA-ATC-ATC-ACG-AA-3') and nts 1348-1369 (5'-TGG-TGA-GGT-TTG-ATC-CGC-ATA-A-3') of human VEGF-A cDNA (244 bp, NM_003376). The PCR primers used for FGF-2 corresponded to nts 629-653 (5'-GAA-GAGCGA-CCC-TCA-CAT-CAA-GCT-A-3') and nts 835-858 (5'-CAG-TTC-GTT-TCA-GTG-CCA-CAT-ACC-3') of human FGF-2 cDNA (230 bp, NM_002006). The PCR primers used for HGF corresponded to nts 250-272 (5'-GCAGAG-GGA-CAA-AGG-AAA-AGA-AG-3') and nts 452-473 (5'-CTA-TTG-AAG-GGG-AAC-CAG-AGG-C-3') of human HGF cDNA (224 bp, NM_000601). The PCR primers used for 18S ribosomal RNA (RS-18) corresponded to nts 184-207 (5'-AAA-GCA-GAC-ATT-GAC-CTC-ACC-AAG-3') and nts 319-341 (5'-AGG-ACC-TGG-CTG-TAT-TTT-CCA-TC-3') of human RS-18 cDNA (158 bp, No.NM_022551). A PCR reaction mixture contaning $2 \mu \mathrm{l}$ of template cDNA, $3 \mathrm{mM}$ $\mathrm{MgCl}_{2}, 0.5 \mu \mathrm{M}$ primers and $2 \mu \mathrm{l}$ of LightCycler-FastStart DNA Master SYBR-Green I mix was prepared in a capillary tube. Q-PCR was carried out in a LightCycler and the PCR products were analyzed using LightCycler data analysis software Ver. 3.5 (Roche). The optimized program involved denaturation at $95^{\circ} \mathrm{C}$ for $10 \mathrm{~min}$, followed by 50 cycles of amplification: at $95^{\circ} \mathrm{C}$ for $10 \mathrm{sec}$, at $60^{\circ} \mathrm{C}$ for $10 \mathrm{sec}$ and at $72^{\circ} \mathrm{C}$ for $10 \mathrm{sec}$ for VEGF-A; at $95^{\circ} \mathrm{C}$ for $10 \mathrm{sec}$, at $60^{\circ} \mathrm{C}$ for $10 \mathrm{sec}$ and at $72^{\circ} \mathrm{C}$ for $8 \mathrm{sec}$ for $\mathrm{KGF}$; at $95^{\circ} \mathrm{C}$ for $10 \mathrm{sec}$, at $63^{\circ} \mathrm{C}$ for $10 \mathrm{sec}$ and at $72^{\circ} \mathrm{C}$ for $10 \mathrm{sec}$ for FGF-2; at $95^{\circ} \mathrm{C}$ for $10 \mathrm{sec}$, at $60^{\circ} \mathrm{C}$ for $10 \mathrm{sec}$ and at $72^{\circ} \mathrm{C}$ for $10 \mathrm{sec}$ for $\mathrm{HGF}$; and at $95^{\circ} \mathrm{C}$ for $10 \mathrm{sec}$, at $64^{\circ} \mathrm{C}$ for $10 \mathrm{sec}$ and at $72^{\circ} \mathrm{C}$ for $7 \mathrm{sec}$ for RS-18. To confirm amplification specificity, $\mathrm{PCR}$ products were subjected to melting curve analysis. Results were expressed as target/RS-18, as an internal standard concentration ratio. Gene expression measurement was performed in triplicate. 


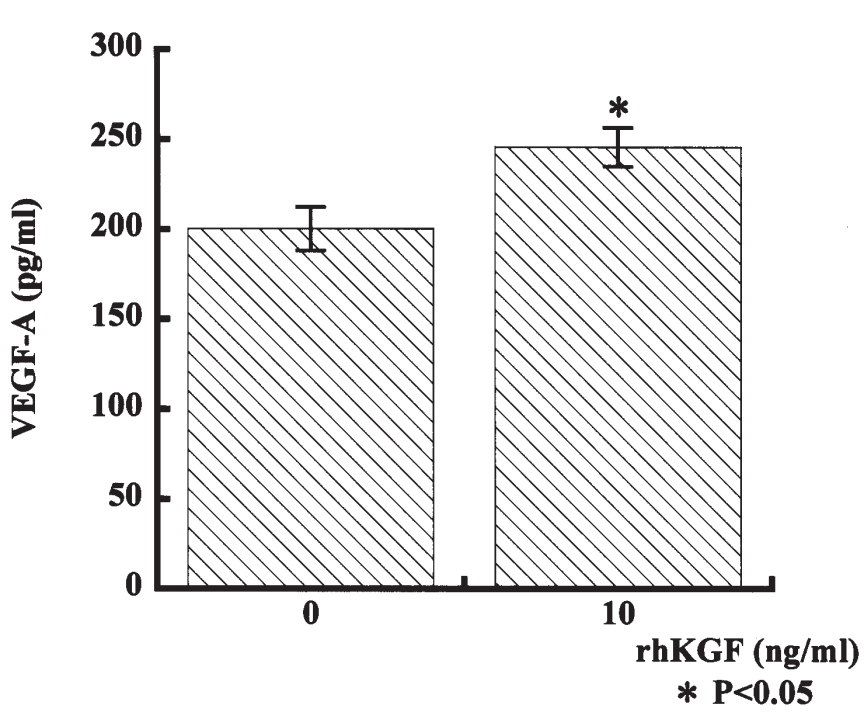

Figure 1. Concentration of VEGF-A protein in culture supernatant of KGFadministered HCT-15 cells. VEGF-A production and secretion of HCT-15 cells in serum-free medium were significantly higher than in untreated control cells, when they were given $10 \mathrm{ng} / \mathrm{ml}$ rhKGF. $\mathrm{P}<0.05$.

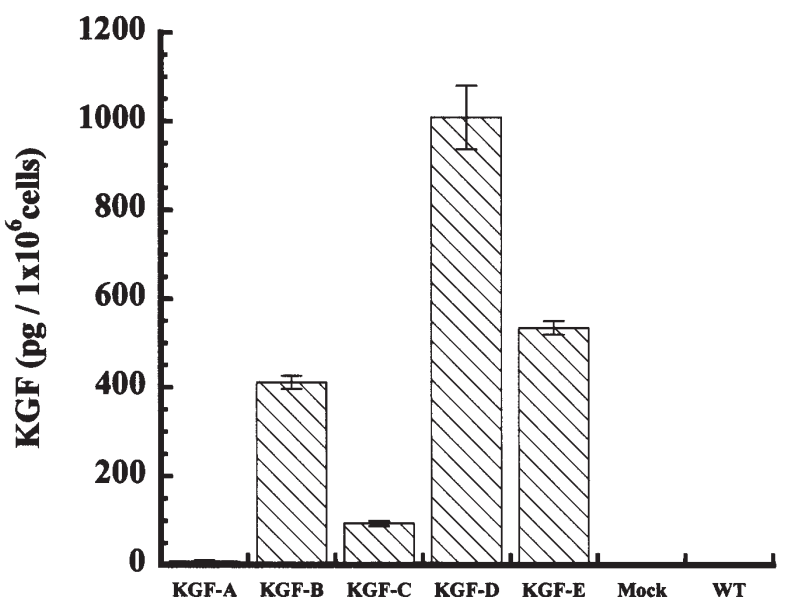

Figure 2. ELISA of KGF concentration in the culture supernatant of KGFtransfected HCT-15 cells. In KGF-transfected HCT-15 cells, KGF protein concentration in culture supernatant increased in four out of five clones (KGF-B to E). KGF protein was not detected in Mock cells and wild-type HCT-15 cells.

Immunofluorescence analyses of KGF and VEGF-A in KGF-transfected HCT-15 cells. KGF-transfected HCT-15 cells and Mock cells (1x105/well) plated in six-well plates were grown in $2 \mathrm{ml}$ of RPMI-1640 medium with $10 \%$ FBS for $24 \mathrm{~h}$ and then cultured in serum-free medium for $48 \mathrm{~h}$. The cells were incubated with anti-KGF (1:50) or VEGF-A antibodies (1:50) in PBS containing $1 \%$ bovine serum albumin (BSA) for $16 \mathrm{~h}$ at $4^{\circ} \mathrm{C}$. As a negative control, HCT-15 cells were incubated with PBS containing $1 \%$ BSA. For VEGF-A staining, the cells were washed with PBS and then incubated with Texas Red-conjugated anti-rabbit IgG for $1 \mathrm{~h}$. For KGF staining, the cells were incubated with biotinylated polyclonal rabbit anti-goat $\mathrm{IgG}$ for $1 \mathrm{~h}$ and then immersed in Texas Red-conjugated streptavidine. The cells were washed with PBS and then mounted with Vectashield mounting medium containing DAPI. Fluorescent images were acquired using a confocal laser scanning microscope Digital Eclipse TE 2000-E (Nikon Insteck Co., Ltd., Tokyo, Japan) and a X100 immersion lens (Nikon Palm Apo VC) with blue diode (BD) and argon (Ar) lasers. The images were analyzed using confocal microscope Digital Eclipse C1 control software EZ-C1 (version 2.30) (Nikon Insteck). The excitation wavelength for Texas Red was $543 \mathrm{~nm}$ and emission was detected and recorded using a 605- to 675-nm band-pass filter. In addition, the excitation wavelength for DAPI was $405 \mathrm{~nm}$ and emission was detected and recorded using a 432- to 446-nm band-pass filter.

ELISA of angiogenic growth factors in culture supernatant of KGF-transfected HCT-15 cells. KGF-transfected HCT-15 cells and Mock cells (1x105/well) plated in six-well plates were grown in $2 \mathrm{ml}$ of RPMI-1640 medium with $10 \%$ FBS for $24 \mathrm{~h}$ and then cultured in serum-free medium for $48 \mathrm{~h}$. The culture supernatants were collected and their KGF, VEGF-A, FGF-2, and HGF concentration were measured using ELISA kits. This study was performed in two separate experiments, each conducted in triplicate.

Statistical analysis. All values were expressed as mean $\pm \mathrm{SE}$. To analyze the effect of rhKGF on HCT-15 cells, Welch's t-test was performed. Mann-Whitney's U test was performed to compare the expression levels of angiogenic growth factors in both groups. $\mathrm{P}<0.05$ was considered significant in all analyses. Computation was performed using the StatView J version 5.0 (SAS Institute, Inc., Cary, NC, USA) software package.

\section{Results}

Effect of rhKGF on concentrations of angiogenic growth factors in culture supernatant of HCT-15 cells. To examine the effect of exogenous KGF on the induction of angiogenic growth factors in colorectal cancer cells, rhKGF was administered to HCT-15 cells. HCT-15 cells were used to examine the paracrine effect of KGF on colorectal cancer cells, because the cells express a very low or a negligible level of KGF and a high level of KGFR (24). The VEGF-A level in the serum-free medium was significantly higher for rhKGF-administered HCT-15 cells than for the untreated control (Fig. 1, p<0.05). However, the FGF-2 and HGF expression levels were too low to detect in the untreated control and rhKGF-administered HCT-15 cells (data not shown).

$K G F, V E G F-A, F G F-2$ and HGF mRNA expression levels in $K G F$-transfected HCT-15 cells. Next, we attempted to clarify the effect of endogenously produced KGF on angiogenic growth factor expression in HCT-15 cells. The protein concentrations of KGF in a culture supernatant of KGFtransfected HCT-15 cells, Mock and wild-type HCT-15 cells were examined by ELISA (Fig. 2). Two clones of KGFtransfected HCT-15 cells (KGF-D and KGF-E), which express a high level of KGF mRNA and Mock cells were used for the following experiments. We examined the expression levels of angiogenic growth factors in Mock, KGF-D and KGF-E cells. 

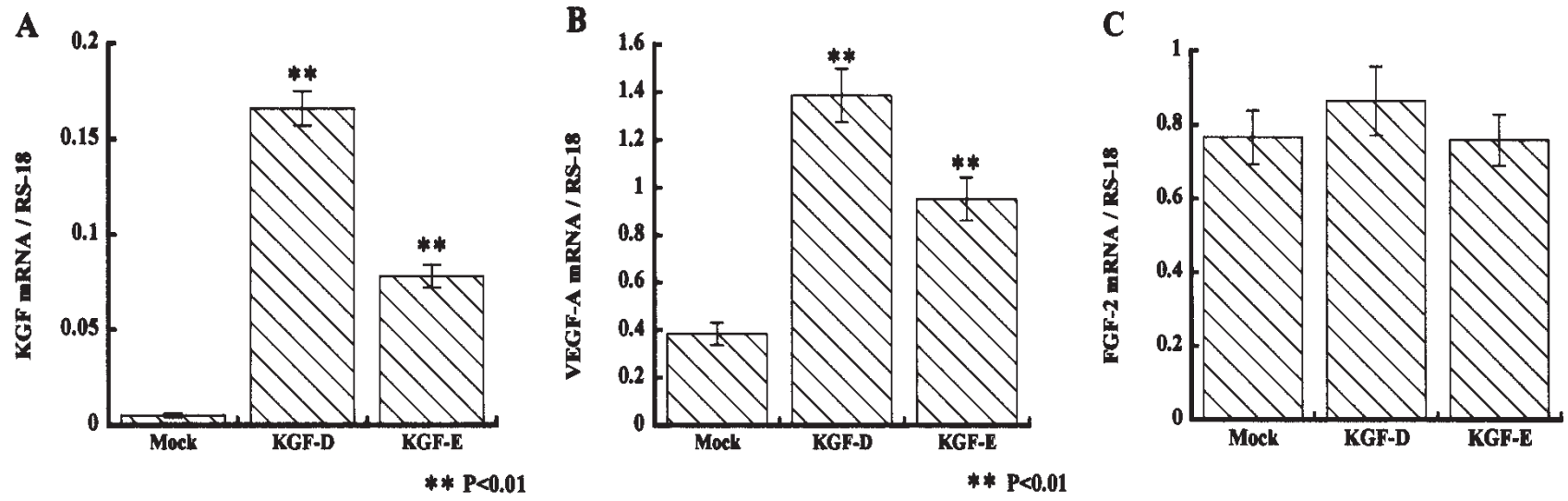

Figure 3. KGF, VEGF-A and FGF-2 mRNA expression levels in KGF-transfected HCT-15 cells. Two clones of stably KGF-transfected HCT-15 cells (KGF-D and KGF-E) expressed significantly higher levels of KGF and VEGF-A mRNAs than HCT-15-mock cells (Mock) (A and B, respectively, p<0.01). In contrast, there were no statistical differences in FGF-2 mRNA level between the two groups (C).
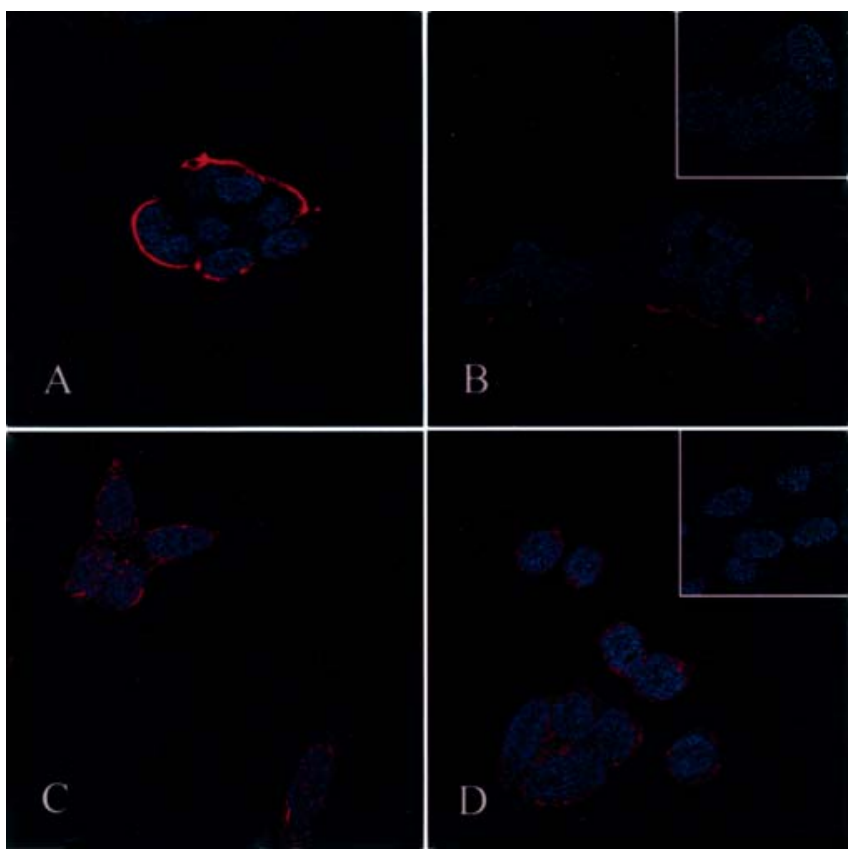

Figure 4. Immunofluorescence analysis of VEGF-A in KGF-transfected HCT-15 cells. KGF and VEGF-A signals were stronger in KGF-E cells (A and C, respectively), than in Mock cells (B and D, respectively). Negative controls without primary antibodies did not present positive signals (B and D, insets).

The expression levels of KGF, VEGF-A, FGF-2 and HGF mRNAs in KGF-D, KGF-E and Mock cells were determined by Q-PCR analysis. KGF-D and KGF-E cells expressed significantly higher levels of KGF and VEGF-A mRNAs than Mock cells ( $p<0.01$, Fig. 3A and B, respectively). In contrast, there were no statistically significant differences in FGF-2 mRNA expression level among KGF-D, KGF-E and Mock cells (Fig. 3C). The HGF mRNA expression level was too low to detect in Mock, KGF-D and KGF-E cells (data not shown).

Immunofluorescence analysis of KGF and VEGF-A localization in KGF-transfected HCT-15 cells. To confirm the increased expression levels of KGF and VEGF-A

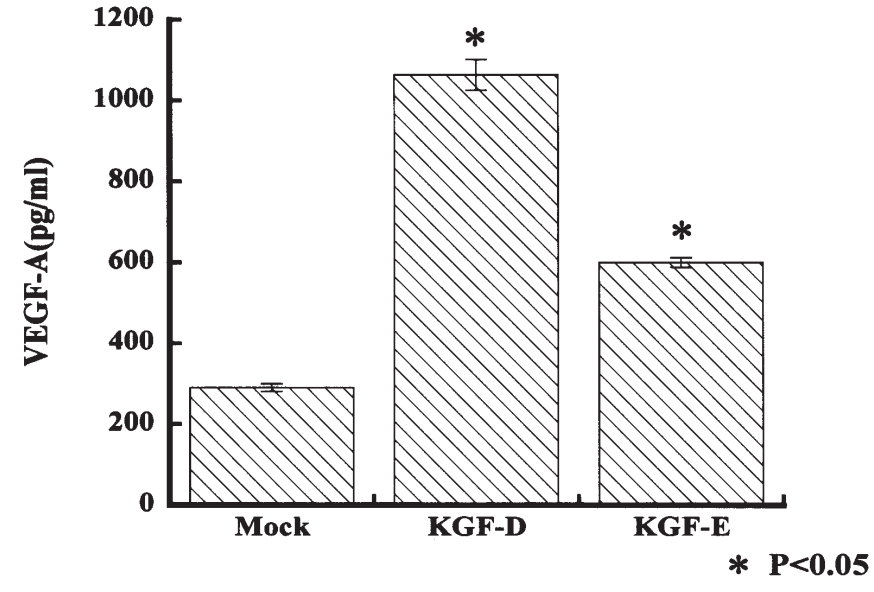

Figure 5. ELISA of VEGF-A expression in culture supernatant of KGFtransfected HCT-15 cells. Compared with the Mock cells, KGF-transfected HCT-15 cells (KGF-D and KGF-E) secreted significantly larger amounts of VEGF-A protein into the culture supernatants. $\mathrm{P}<0.05$.

proteins in the cytoplasm of KGF-transfected HCT-15 cells, immunofluorescence analysis was performed. KGF signals were stronger at the periphery of the cytoplasm of KGF-E cells than at that of Mock cells (Fig. 4A and B, respectively). VEGF-A signals were diffuse and stronger in the cytoplasm of KGF-E cells than in that of Mock cells (Fig. 4C and D, respectively). Negative controls without primary antibodies did not show any positive signals (B and D, insets).

Concentrations of angiogenic growth factors in the culture supernatant of KGF-transfected HCT-15 cells. To estimate whether the angiogenic growth factors were effectively secreted into the extracellular space, ELISA of the VEGF-A, FGF-2 and HGF proteins in the culture supernatant was performed. Compared with the culture supernatant of Mock cells, the culture supernatant of KGF-transfected HCT-15 cells (KGF-D and KGF-E) contained significantly higher concentrations of VEGF-A ( $p<0.05$, Fig. 5). FGF-2 and HGF protein concentrations were too low to detect by sandwich ELISA in both groups (data not shown). 


\section{Discussion}

Several studies showing exogenous KGF involvement in tumorigenesis have been reported. Exogenous KGF stimulated the growth of 5 of 35 human solid tumor cell lines, which were two lung, one stomach, one breast and one colorectal cancer cell lines. In five colorectal cancer cell lines, rhKGF stimulated the growth of only one cancer cell line, namely, LOVO (25). KGF stimulates motility of estrogen receptor (ER)-positive breast cancer cells and gastric cancer cells $(26,27)$. We have recently reported that KGF increases the adhesion activity of the ER and progesterone receptor (PR)-positive welldifferentiated endometrial cancer cells to fibronectin and does not stimulate cell growth (9). These findings suggest that the KGF-KGFR system modulates cell growth and other biological functions.

Recently, we have found that exogenous KGF increases the expression and secretion levels of VEGF-A in pancreatic cancer cells (10). VEGF-A, which is induced by exogenous $\mathrm{KGF}$, may stimulate the growth of pancreatic cancers through tumor angiogenesis. In colorectal cancer, we found in this study, that rhKGF induced VEGF-A expression. KGF is reported to activate nuclear factor $\kappa \mathrm{B}(\mathrm{NF}-\kappa \mathrm{B})$, which in turn induces the expression of VEGF-A, MMP-9 and urokinase-type plasminogen activators and also stimulates migration and invasion of human pancreatic ductal epithelial cells (28). A similar intracellular pathway may exist in colorectal cancer cells. To the best of our knowledge, this is the first study showing that KGF induces VEGF-A in colorectal cancer. Our group previously reported that KGFR is expressed in $62.5 \%$ of colorectal cancer patients and KGF is highly expressed in enterochromaffin cells and fibroblasts located close to cancer cells (11). These findings may indicate that KGF, synthesized by other cell types or exogenously administered, plays significant roles in colorectal cancer cell growth and/or distant metastasis through the formation of neovasculature adjacent to cancer cells.

A human KGF product named palifermin has already been introduced in medical treatment. Palifermin is produced by recombinant DNA technology in Escherichia coli and it differs from endogenous human KGF in that the first $23 \mathrm{~N}$ terminal amino acids have been deleted to improve protein stability. Palifermin is clinically used to treat gingivostomatitis and oral ulcers that are caused by chemotherapy and/or radiation for bone marrow transplantation to leukemia patients (29). In a randomized phase II clinical trial in advanced colorectal cancer patients treated with 5-FU and leucovorin, the patients who received palifermin had a lower incidence of ulcerative oral mucositis and their prognosis was nearly the same as that of the control group (30). However, palifermin has not been fully tested for all types of cancer (12). Our findings suggest that further studies may be necessary to determine whether palifermin can be safely used in KGFR-expressing types of malignant tumor cells such as colorectal cancer. In contrast to VEGF-A, exogenous KGF did not stimulate the expression and secretion of FGF-2 and HGF in colorectal cancer cells. FGF-2 and HGF are also important angiogenic factors in some types of cancer cells and they have putative NF- $\mathrm{KB}$ binding sites in the promoter region. The reason KGF induced VEGF-A, but not FGF-2 or
HGF is unclear. Each promoter activity may cause different expression patterns of the angiogenic growth factors. Further studies are required to clarify the effects of KGF on tumor angiogenesis in vivo.

We previously examined the biological role of KGF in HCT-15 cells (24). HCT-15 cells express a high level of KGFR, but a very low or a negligible level of KGF. The growth rate is not altered in stably KGF-transfected HCT-15 cells, but the activity of adhesion to type IV collagen through ERK and FAK signaling pathways increases in the cells in vitro. In this study, KGF-transfected HCT-15 cells produced significantly larger amounts of KGF and VEGF-A than Mock cells. This study may indicate that the overexpression of KGF genes in tumor cells increases VEGF-A production and the KGF-KGFR autocrine loop contributes to VEGF production in cancer cells. We have recently reported that coexpression of KGF and KGFR in pancreatic cancer cells strongly correlates with VEGF-A expression and venous invasion of cancer cells (10). KGF short hairpin (sh) RNA-transfected pancreatic cancer cells express a lower level of KGF and attenuate VEGF-A expression and release in culture medium. Coexpression of KGF and KGFR was previously reported in colorectal cancer cells and anti-VEGF therapy is now used for patients who suffer from various cancers including colorectal cancer. The anti-VEGF therapy may be a more effective treatment for KGF/KGFR coexpressing colorectal cancer patients. Further study is required to clarify the correlation of KGF and KGFR coexpression with VEGF-A expression in colorectal cancer patients.

In summary, exogenous and endogenous KGF induced the expression of VEGF-A, but not FGF-2 and HGF in colorectal cancer cells. VEGF-A induced by KGF may contribute to the aggressiveness of colorectal cancer through tumor angiogenesis.

\section{Acknowledgements}

The authors appreciate Mr. Kiyoshi Teduka, Ms. Taeko Suzuki and Dr Norio Motoda (Integrative Oncological Pathology, Nippon Medical School) for excellent technical assistance. We also thank Dr Mitsuhiro Kudo (Integrative Oncological Pathology, Nippon Medical School) and Dr Shunji Ishiwata (Department of Pharmaceutics, Kinki University) for invaluable advice. This study was supported in part by a Grant-in-Aid for Scientific Research (C, No. 19591603 for Z.N.) from the Japan Society for the Promotion of Science and by a Grant-in-Aid for Young Scientists from the Japan Society for the Promotion of Science to Tetsushi Yamamoto (B, No. 20790974).

\section{References}

1. Rubin JS, Osada H, Finch PW, Taylor WG, Rudikoff S and Aaronson SA: Purification and characterization of a newly identified growth factor specific for epithelial cells. Proc Natl Acad Sci USA 86: 802-806, 1989.

2. Finch PW, Rubin JS, Miki T, Ron D and Aaronson SA: Human KGF is FGF-related with properties of a paracrine effector of epithelial cell growth. Science 245: 752-755, 1989.

3. Rubin JS, Bottaro DP, Chedid M, Miki T, Ron D, Cheon G, Taylor WG, Fortney E, Sakata H, Finch PW, et al: Keratinocyte growth factor. Cell Biol Int 19: 399-411, 1995. 
4. Miki T, Bottaro DP, Fleming TP, Smith CL, Burgess WH, Chan AM and Aaronson SA: Determination of ligand-binding specificity by alternative splicing: two distinct growth factor receptors encoded by a single gene. Proc Natl Acad Sci USA 89: 246-250, 1992.

5. Ornitz DM and Itoh N: Fibroblast growth factors. Genome Biol 2: Reviews S3005, 2001.

6. Putnins EE, Firth JD, Lohachitranont A, Uitto VJ and Larjava H: Keratinocyte growth factor (KGF) promotes keratinocyte cell attachment and migration on collagen and fibronectin. Cell Adhes Commun 7: 211-221, 1999.

7. Gillis P, Savla U, Volpert OV, Jimenez B, Waters CM, Panos RJ and Bouck NP: Keratinocyte growth factor induces angiogenesis and protects endothelial barrier function. J Cell Sci 112: 20492057, 1999

8. Yoshino M, Ishiwata T, Watanabe M, Matsunobu T, Komine O, Ono Y, Yamamoto T, Fujii T, Matsumoto K, Tokunaga A and Naito Z: Expression and roles of keratinocyte growth factor and its receptor in esophageal cancer cells. Int J Oncol 31: 721-728, 2007.

9. Ishikawa A, Kudo M, Nakazawa N, Onda M, Ishiwata T, Takeshita T and Naito Z: Expression of keratinocyte growth factor and its receptor in human endometrial cancer in cooperation with steroid hormones. Int J Oncol 32: 565-574, 2008.

10. Cho K, Ishiwata T, Uchida E, Nakazawa N, Korc M, Naito Z and Tajiri T: Enhanced expression of keratinocyte growth factor and its receptor correlates with venous invasion in pancreatic cancer. Am J Pathol 170: 1964-1974, 2007.

11. Watanabe M, Ishiwata T, Nishigai K, Moriyama Y and Asano G: Overexpression of keratinocyte growth factor in cancer cells and enterochromaffin cells in human colorectal cancer. Pathol Int 50: 363-372, 2000

12. Finch PW and Rubin JS: Keratinocyte growth factor expression and activity in cancer: implications for use in patients with solid tumors. J Natl Cancer Inst 98: 812-824, 2006.

13. Matsunobu T, Ishiwata T, Yoshino M, Watanabe M, Kudo M, Matsumoto K, Tokunaga A, Tajiri T and Naito Z: Expression of keratinocyte growth factor receptor correlates with expansive growth and early stage of gastric cancer. Int J Oncol 28: 307-314, 2006.

14. Yoshino M, Ishiwata T, Watanabe M, Komine O, Shibuya T, Tokunaga A and Naito Z: Keratinocyte growth factor receptor expression in normal colorectal epithelial cells and differentiated type of colorectal cancer. Oncol Rep 13: 247-252, 2005.

15. Distler JH, Hirth A, Kurowska-Stolarska M, Gay RE, Gay S and Distler O: Angiogenic and angiostatic factors in the molecular control of angiogenesis. Q J Nucl Med 47: 149-161, 2003.

16. Ferrara N, Gerber HP and LeCouter J: The biology of VEGF and its receptors. Nat Med 9: 669-676, 2003.

17. Gospodarowicz D: Localisation of a fibroblast growth factor and its effect alone and with hydrocortisone on 3T3 cell growth. Nature 249: 123-127, 1974.

18. Takahashi M, Ota S, Shimada T, Hamada E, Kawabe T, Okudaira T, Matsumura M, Kaneko N, Terano A, Nakamura T, et al: Hepatocyte growth factor is the most potent endogenous stimulant of rabbit gastric epithelial cell proliferation and migration in primary culture. J Clin Invest 95: 1994-2003, 1995.
19. Igawa T, Kanda S, Kanetake H, Saitoh Y, Ichihara A, Tomita Y and Nakamura T: Hepatocyte growth factor is a potent mitogen for cultured rabbit renal tubular epithelial cells. Biochem Biophys Res Commun 174: 831-838, 1991.

20. Presta M, Dell'Era P, Mitola S, Moroni E, Ronca R and Rusnati M: Fibroblast growth factor/fibroblast growth factor receptor system in angiogenesis. Cytokine Growth Factor Rev 16: 159-178, 2005.

21. Hansen S, Grabau DA, Rose C, Bak M and Sorensen FB: Angiogenesis in breast cancer: a comparative study of the observer variability of methods for determining microvessel density. Lab Invest 78: 1563-1573, 1998.

22. Schoell WM, Pieber D, Reich O, Lahousen M, Janicek M, Guecer F and Winter R: Tumor angiogenesis as a prognostic factor in ovarian carcinoma: quantification of endothelial immunoreactivity by image analysis. Cancer 80: 2257-2262, 1997.

23. Tomisaki S, Ohno S, Ichiyoshi Y, Kuwano H, Maehara Y and Sugimachi K: Microvessel quantification and its possible relation with liver metastasis in colorectal cancer. Cancer 77 : 1722-1728, 1996

24. Kudo M, Ishiwata T, Nakazawa N, Kawahara K, Fujii T, Teduka K and Naito Z: Keratinocyte growth factor-transfectionstimulated adhesion of colorectal cancer cells to extracellular matrices. Exp Mol Pathol 83: 443-452, 2007.

25. Oelmann E, Haghgu S, Kulimova E, Mesters RM, Kienast J, Herbst H, Schmitmann C, Kolkmeyer A, Serve H and Berdel WE: Influence of keratinocyte growth factor on clonal growth of epithelial tumor cells, lymphoma and leukemia cells and on sensitivity of tumor cells towards 5-fluorouracil in vitro. Int J Oncol 25: 1001-1012, 2004

26. Zang XP and Pento JT: Keratinocyte growth factor-induced motility of breast cancer cells. Clin Exp Metastasis 18: 573-580, 2000.

27. Shin EY, Lee BH, Yang JH, Shin KS, Lee GK, Yun HY, Song YJ, Park SC and Kim EG: Up-regulation and coexpression of fibroblast growth factor receptors in human gastric cancer. J Cancer Res Clin Oncol 126: 519-528, 2000.

28. Niu J, Chang Z, Peng B, Xia Q, Lu W, Huang P, Tsao MS and Chiao PJ: Keratinocyte growth factor/fibroblast growth factor7-regulated cell migration and invasion through activation of NF-kappaB transcription factors. J Biol Chem 282: 6001-6011, 2007.

29. McDonnell AM and Lenz KL: Palifermin: role in the prevention of chemotherapy - and radiation-induced mucositis. Ann Pharmacother 41: 86-94, 2007.

30. Rosen LS, Abdi E, Davis ID, Gutheil J, Schnell FM, Zalcberg J, Cesano A, Gayko U, Chen MG and Clarke S: Palifermin reduces the incidence of oral mucositis in patients with metastatic colorectal cancer treated with fluorouracil-based chemotherapy. J Clin Oncol 24: 5194-5200, 2006. 